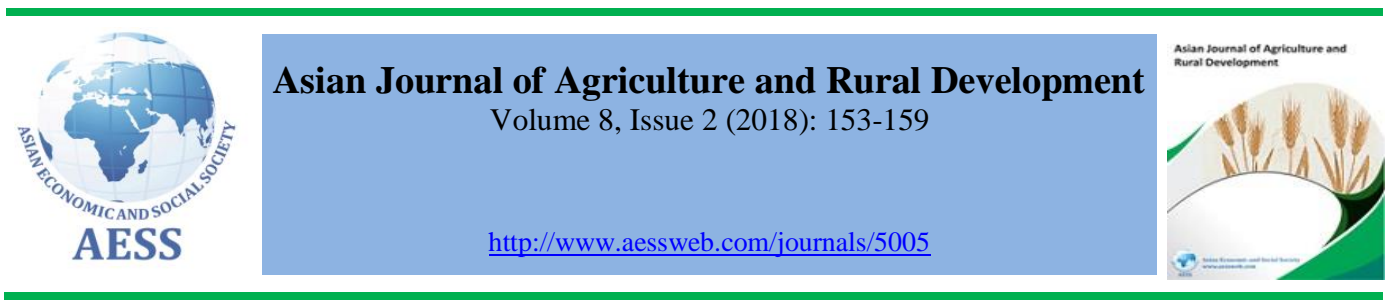

\title{
TRENDS AND VARIABILITY OF WHEAT CROP IN PAKISTAN
}

Saleem Abid ${ }^{\mathrm{a}}$

M. Asif Masood ${ }^{a}$

M. Zubair Anwar ${ }^{\mathrm{a}}$

Saleem Zahid ${ }^{\mathrm{b}}$

Irum Raza ${ }^{a}$ a Statistics and Computing Program, Social Sciences Research Institute, PARC National Agricultural Research Centre, Islamabad, Pakistan.

${ }^{\mathrm{b}}$ Institute of Business and Management Sciences, The University of Agriculture, Peshawar, Pakistan.

\saleemabidpk@gmail.com (Corresponding author)

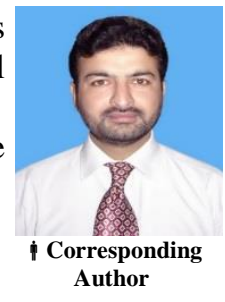

Author

\section{ARTICLE HISTORY:}

Received: 18-Oct-2018

Accepted: $29-\mathrm{Dec}-2018$

Online Available: 17-Jan2019

\section{Keywords:}

Trend,

Growth,

Variability,

Semi-log model,

Wheat crop

\begin{abstract}
The main focus of the study was to analyze trends and variability of wheat crop in Pakistan. Semi-log trend model was used to find trends and growth rate in area, yield and production of wheat crop whereas the variability was measured by Cuddy-Della Valle index of variability. The findings of the study illustrate that wheat area in Punjab, Sindh and Baluchistan was increased over the time whereas cultivated area of wheat in Khyber Pakhtunkhwa province was marginally decreased during 1981-85 to 2011-15. The results show that there was substantial increase in wheat yield and production in all four provinces of Pakistan. The increase in wheat yield may due to the adoption of new varieties of wheat in the country over the time. It was also concluded from the results that area and yield of wheat in Baluchistan recorded the highest degree of variability whereas in Punjab province area and yield of wheat crop were noticed the lowest degree of variability. Similarly, the maximum variability in wheat production was recorded for Baluchistan province followed by Sindh, Khyber Pakhtunkhwa, and Punjab. Mostly the variability in wheat production was due to the variability in wheat area and their yield.
\end{abstract}

\section{Contribution/ Originality}

The present study was conducted to examine the growth and variability in area, production and yield of wheat crop in all provinces (i.e. Khyber Pakhtunkhwa, Baluchistan, Sindh and Punjab) of Pakistan. Information on growth performance and variability in wheat production would help the policy makers of the country to implement policy measures regarding the wheat crop.

DOI: 10.18488/journal.1005/2018.8.2/1005.2.153.159

ISSN (P): 2304-1455/ISSN (E):2224-4433

How to cite: Saleem Abid, M. Asif Masood, M. Zubair Anwar, Saleem Zahid and Irum Raza (2018). Trends and variability of wheat crop in Pakistan. Asian Journal of Agriculture and Rural Development, 8(2), 153-159.

(C) 2018 Asian Economic and Social Society. All rights reserved. 


\section{INTRODUCTION}

Agriculture sector plays an important role in the economy of Pakistan which contributes 18.9 percent to GDP and absorbs 42.3 percent of labour force (Government of Pakistan, 2018). Wheat is grown extensively in Pakistan on a subsistence basis for home consumption. On average, the households incur 12.55 percent of the monthly expenditures on wheat and wheat flour (Government of Pakistan, 2017). The per capita wheat production in Pakistan is $131 \mathrm{kgs}$ per year, while per capita wheat consumption is $118 \mathrm{kgs}$ per year which is highest in the world (Govt. Khyber Pakhtunkhwa, 2014). Wheat productivity and yield are the important determinants of wheat supply. Availability of adequate food is of major concern at household, provincial and country level for food security. Any variation in the supply and demand of wheat in world market affects the welfare of farmers, consumers, taxpayers and those directly or indirectly dependent on agriculture (Jehangir et al., 2008; Hong-juan et al., 2017).

Variability is an important measure of decision making in the dynamics of development and agricultural production. To analyze variations in crop production regardless of growth, it is important to understand the nature of income stability and food security. The variations in crop production affect prices and cause sharp fluctuations, but also lead to significant differences in income available to farmers. The magnitude of the variations depends on the nature of crop production technology, its sensitivity to weather, availability of inputs, economic environment, and several other factors (Wasim, 2011). Hazell (1989) found that due to the adoption of modern technology, global food grain production and the production of Indian food grains increased. Mehra (1981) argued that the variability in grain production has increased in India due to improved technological progress from the mid-1960s to large scale. Wasim (2001) evaluated that due to adoption of high yielding varieties and new farm technologies the variability in production increases. Similar opinions are also put forward by Ray (1983), Parthasarathy (1984), Mitra (1990) and Singh and Issac (2018). As wheat is a staple food of the country so it occupies a central place in Pakistan's agricultural policies. The present study was conducted to examine the growth and variability in area, production and yield of wheat crop in all provinces (i.e. Khyber Pakhtunkhwa, Baluchistan, Sindh and Punjab) of Pakistan. Information on growth performance and variability in wheat production would help the policy makers of the country to implement policy measures regarding the wheat crop.

\section{MATERIALS AND METHOD}

A time series data from 1980-81 to 2014-15 on area, yield and production of wheat for Baluchistan, Khyber Pakhtunkhwa (KP), Punjab and Sindh provinces was collected from different issues of Agricultural Statistics of Pakistan.

\subsection{Linear semi-log trend function}

In order to find trends and estimate growth rate in area, yield and production of wheat crop semi$\log$ trend function was used (Abid et al., 2014).

$$
\ln Z=\beta_{0}+\beta_{l} W+e
$$

where

$Z=$ dependent variable (area, production and yield of wheat crop);

$\beta_{l}=$ trend coefficient; $\mathrm{W}=$ trend over specific period;

$\ln =$ natural logarithm; and $\mathrm{e}=$ error term

To find out the compound growth rate the following formula was used (Gujarati, 2004). $r=\left\{\operatorname{antilog}\left(\beta_{1}\right)-1\right\}^{*} 100$ 
where

$\mathrm{r}=$ Compound growth rate and $\beta_{1}=$ trend coefficient.

\subsection{Measurement of variability}

The variability in wheat area, yield and production was measured by Cuddy-Della Valle index of variability (1978) that is applied by different researchers in time series data. The formula for Cuddy-Della Valle Index of Variability (I) is

$$
\mathrm{I}=\mathrm{CV}^{*} \sqrt{\left(1-R^{2}\right.}
$$

where $\mathrm{CV}$ represent the coefficient of variation; and $\mathrm{R}^{2}$ is coefficient of determination from a timetrend regression.

\section{RESULTS AND DISCUSSION}

\subsection{Trends analysis of wheat crop}

Trends in wheat area, yield and production were presented in Table-1. The results from the table shows that the wheat area in Pakistan during 1981-85 was 7309 thousand hectares as compared to 8783 thousand hectares sown during 2011-15, which displays that wheat area increased by 22.2 percent over the time. The production of wheat was increased from 12053 thousand tonnes to 24688 thousand tonnes during 1981-85 to 2011-15, which indicate that wheat production in Pakistan was increased by 104.8 percent. It may be due to the corresponding increase in wheat area in Pakistan and also increase in wheat yield per hectare (67.8 percent) (Table 1 \& Figure 1).

Results of the study also illustrate that the wheat area in Punjab, Sindh, Khyber Pakhtunkhwa and Baluchistan was 5242,1021, 784 and 262 thousand hectares during 1981-85 whereas it was 6719, 1084,742 and 384 thousand hectares in 2011-15, respectively. So that the area under wheat crop in Punjab (28.2 percent), Sindh (6.2 percent) and Baluchistan (46.6 percent) was increased over the time. But the cultivated area of wheat crop in Khyber Pakhtunkhwa province was decreased by 5.4 percent during 1981-85 to 2011-15.

Table 1: Trend of wheat crop in Pakistan, 1981-82 to 2014-15

(5-year averages)

\begin{tabular}{lccccc}
\hline Year & Punjab & Sindh & Khyber Pakhtunkhwa & Balochistan & Pakistan \\
\hline & & & (Area in "000" Hectares) & \\
$1981-85$ & 5242 & 1021 & 784 & 262 & 7309 \\
$1986-90$ & 5577 & 1041 & 809 & 273 & 7700 \\
$1991-95$ & 5855 & 1087 & 850 & 359 & 8152 \\
$1996-00$ & 6029 & 1061 & 843 & 334 & 8268 \\
$2001-05$ & 6263 & 888 & 738 & 334 & 8223 \\
$2006-10$ & 6655 & 1048 & 751 & 387 & 8841 \\
$2011-15^{*}$ & 6719 & 1084 & 742 & 384 & 8929 \\
$1981-85$ & 8653 & 2085 & (Production in "000" Tonnes) & 407 & 12053 \\
$1986-90$ & 9817 & 2232 & 907 & 527 & 13598 \\
$1991-95$ & 11919 & 2313 & 1023 & 788 & 16193 \\
$1996-00$ & 14258 & 2601 & 1173 & 707 & 18661 \\
$2001-05$ & 15948 & 2328 & 1095 & 649 & 19960 \\
$2006-10$ & 17768 & 3670 & 1149 & 875 & 23362 \\
$2011-15^{*}$ & 18837 & 3759 & 1253 & & 24688 \\
$1981-85$ & 1649 & 2042 & Yield in kgs per hectare & 1551 & 1648 \\
\hline
\end{tabular}




\begin{tabular}{llllll}
\hline $1986-90$ & 1759 & 2144 & 1261 & 1945 & 1765 \\
$1991-95$ & 2035 & 2128 & 1379 & 2202 & 1986 \\
$1996-00$ & 2361 & 2466 & 1291 & 2114 & 2255 \\
$2001-05$ & 2544 & 2618 & 1402 & 1948 & 2426 \\
$2006-10$ & 2669 & 3497 & 1531 & 1994 & 2642 \\
$2011-15 *$ & 2803 & 3468 & 1688 & 2185 & 2765 \\
\hline \multicolumn{2}{l}{ Source: Government of Pakistan. 1990-2017 }
\end{tabular}

The average production of wheat crop in Punjab, Sindh, Khyber Pakhtunkhwa and Baluchistan provinces were $8653,2085,907$ and 407 thousand tonnes during 1981-85 whereas it was $18837,3759,1253$ and 840 thousand tons during 2011-15, respectively. The results shows that there was a substantial increase in production of wheat crop in all provinces of Pakistan. Similarly, it was exposed from the results that the yield of wheat crop was significantly increased in Punjab (70 percent), Sindh (69.8 percent), Khyber Pakhtunkhwa (45.8 percent) and Baluchistan (40.9 percent); it may be due to the introduction of new wheat varieties in the country over the time.

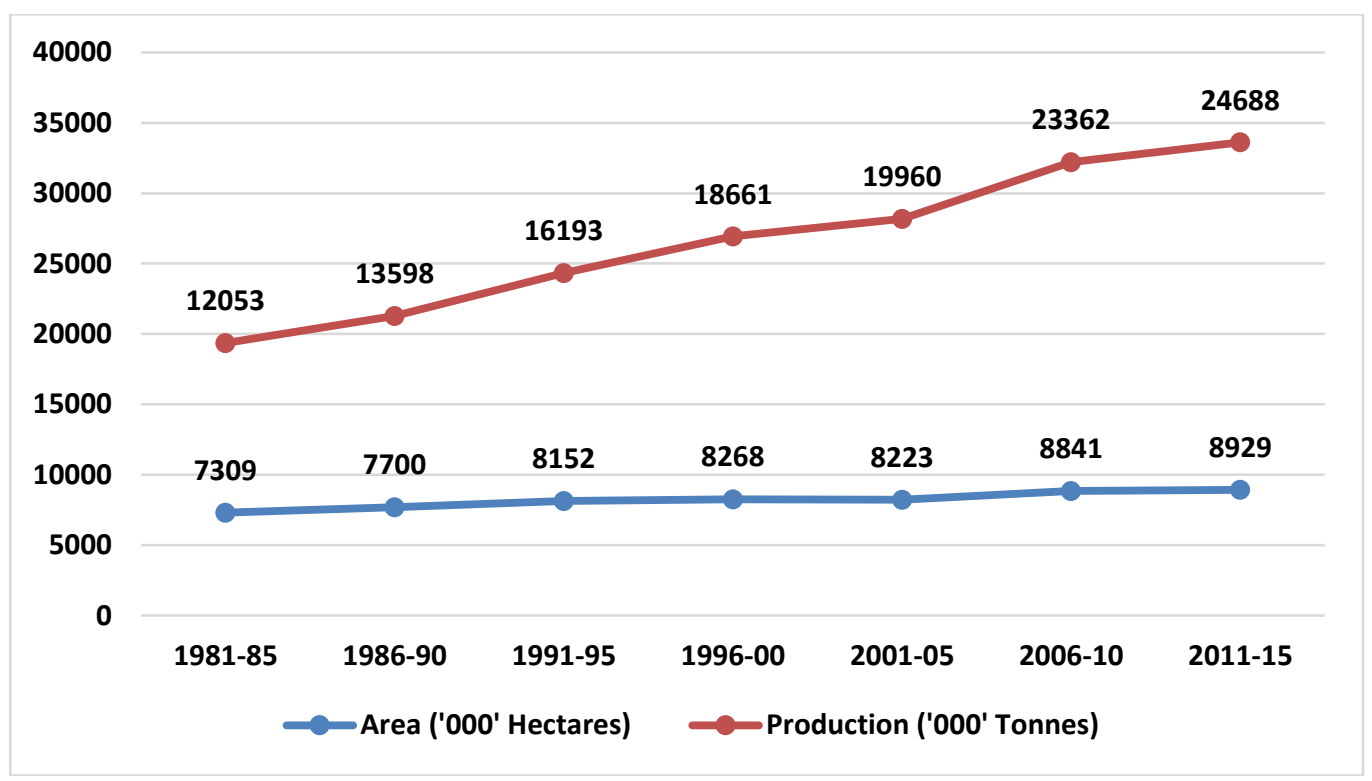

Figure 1: Trend in area and production of wheat crop in Pakistan, 1981-82 to 2011-15

\subsection{Growth analysis of wheat crop}

Estimated growth rates of wheat Crop during 1981-82 to 2014-15 were accessible in Table-2. It was revealed from the outputs that the semi log models were statistically significant for wheat area, yield and production in all provinces of Pakistan but wheat area model for Sindh province was statistically non-significant. The sign of trend co-efficient for yield and production of wheat was positive for all models of four provinces of Pakistan except wheat area for Khyber Pakhtunkhwa and Sindh provinces where the sign of trend co-efficient were negative. The positive sign of growth rate explain that wheat area, yield and production in Pakistan was increased at a rate of 0.65 percent, 1.90 percent and 2.56 percent per year, respectively. 
Table 2: Estimated growth rate of wheat crop in Pakistan, 1981-82 to 2014-15

\begin{tabular}{lcccc}
\hline Wheat/Region & $\begin{array}{c}\text { Coefficient of } \\
\text { Determination }\left(\mathbf{R}^{2}\right)\end{array}$ & $\begin{array}{c}\text { Trend } \\
\text { Coefficient }(\mathbf{b})\end{array}$ & t-Statistic & $\begin{array}{c}\text { Growth } \\
\text { Rate (\%) }\end{array}$ \\
\hline Area & 86.4 & 0.00651 & $14.26^{* * *}$ & 0.65 \\
Pakistan & 23.8 & -0.00316 & $-3.16^{* *}$ & -0.32 \\
Khyber & 94.3 & 0.00858 & $22.92^{* *}$ & 0.86 \\
Pakhtunkhwa & 0.10 & -0.00033 & $-0.21^{\text {NS }}$ & -0.03 \\
Punjab & 52.0 & 0.0133 & $5.89^{* *}$ & 1.34 \\
Sindh & & & & \\
Baluchistan & 95.2 & 0.0253 & $25.19^{* *}$ & 2.56 \\
Production & 30.2 & 0.00755 & $3.72^{* *}$ & 0.76 \\
Pakistan & 94.0 & 0.0283 & $22.40^{* *}$ & 2.87 \\
Khyber & 69.6 & 0.0196 & $8.56 * *$ & 1.98 \\
Pakhtunkhwa & 50.2 & 0.0198 & $5.68^{* *}$ & 2.00 \\
Punjab & & & & \\
Sindh & 93.4 & 0.0188 & $21.24 * *$ & 1.90 \\
Baluchistan & 59.6 & 0.0107 & $6.87^{* *}$ & 1.08 \\
Yield & 89.6 & 0.0197 & $16.6^{* *}$ & 1.99 \\
Pakistan & 83.4 & 0.0199 & $12.6^{* *}$ & 2.01 \\
Khyber & 19.8 & 0.00654 & $2.81^{* *}$ & 0.66 \\
Pakhtunkhwa & & & \\
Punjab & Sindh & & & \\
Baluchistan & & & & \\
\hline
\end{tabular}

**Significant at $1 \%$ level of significance; NS=Non significant

Table 2 illustrate that the compound growth rate for wheat area in Punjab and Baluchistan provinces were 0.86 percent and 1.34 percent, respectively. It means that the area under wheat crop in these two provinces were increasing at a rate of 0.86 percent and 1.34 percent per annum. In contrast, compound growth rate for wheat area of Khyber Pakhtunkhwa and Sindh were -0.32 and -0.03 percent, which indicate that area under wheat crop was decreased at the rate of 0.32 percent and 0.03 percent per annum in these two provinces, respectively. It was also exposed from the results that the compound growth rate of wheat production for Khyber Pakhtunkhwa, Punjab, Sindh and Baluchistan were 0.76, 2.87, 1.98 and 2.00 percent respectively, which explain that the production of wheat crop in the four provinces were increased at the rate of $0.76,2.87,1.98$ and 2.00 percent per annum. The data also indicate that the yield of wheat crop in Pakistan as well as in all the four provinces were increased.

\subsection{Variability in wheat crop}

The estimated relative variability index in wheat crop during 1981-82 to 2014-15 was presented in Table 3. It may be observed from the results that area and yield of wheat crop in Baluchistan recorded the highest degree of variability whereas in Punjab province area and yield of wheat crop were noticed the lowest degree of variability. Similarly, the maximum variability in wheat production was recorded for the Baluchistan province followed by Sindh, Khyber Pakhtunkhwa, and Punjab. Mostly the fluctuation in wheat production was due to the fluctuations in area under wheat crop and their yield. According to Goswami and Challa (2006), if variability in both area and yield components decline, then the variability in production is bound to decline. This is true with respect to wheat crop in Pakistan (Table-3). The results shows that the variability in wheat production had increased with the increased variability in area and yield, it may be due to the adoption of new technology. 
Table 3: Variability in wheat crop of Pakistan during 1981-82 to 2014-15

\begin{tabular}{lccc}
\hline Provinces & For Area & $\begin{array}{c}\text { Instability Index } \\
\text { For Production }\end{array}$ & For yield \\
\hline Punjab & 2.1 & 6.0 & 5.8 \\
Sindh & 8.4 & 14.6 & 10.1 \\
Khyber Pakhtunkhwa & 5.8 & 11.0 & 8.2 \\
Balochistan & 11.7 & 18.8 & 12.7 \\
Pakistan & 2.5 & 5.2 & 4.5 \\
\hline
\end{tabular}

Source: Author's own calculation

\section{CONCLUSION}

The results illustrate that the area under wheat in Punjab, Sindh and Baluchistan were increased over the time whereas cultivated area of wheat in Khyber Pakhtunkhwa province was marginally decreased during 1981-85 to 2011-15. The results show that there was significant increase in wheat yield and their production in the four provinces of Pakistan. The increase in yield of wheat was possibly due to the introduction of new varieties in the country over the time. The semi log models were statistically significant for wheat area, yield and production in all provinces of Pakistan except wheat area model for Sindh province which was statistically non-significant. It may be observed that area and yield of wheat in Baluchistan recorded highest degree of variability whereas in Punjab province area and yield of wheat were noticed lowest degree of variability. Similarly maximum variability in wheat production was recorded for the Baluchistan province followed by Sindh, Khyber Pakhtunkhwa, and Punjab. Mostly the variation in wheat production was due to the fluctuations in wheat area and their yield. The variability in wheat had increased, it may be due to the adoption of new varieties and better methods of cultivation, increase in variability of rainfall and prices and so on.

Funding: This study received no specific financial support.

Competing Interests: The authors declared that they have no conflict of interests.

Contributors/Acknowledgement: All authors participated equally in designing and estimation of current research.

Views and opinions expressed in this study are the views and opinions of the authors, Asian Journal of

Agriculture and Rural Development shall not be responsible or answerable for any loss, damage or

liability etc. caused in relation to/arising out of the use of the content.

\section{References}

Abid, S., Shah, N. A., Hassan, A., Farooq, A., \& Masood, A. (2014). Growth and trend in area, production and yield of major crops of Khyber Pakhtunkhwa, Pakistan. Asian Journal of Agriculture and Rural Development, 4(2), 149-155. view at Google scholar

Cuddy, J. D. A., \& Della, V. P. A. (1978). Measuring of instability of time series data. Oxford Bulletin of Economics and Statistics, 40(1), 79-85. view at Google scholar

Government of Pakistan. (2017). Household integrated economic survey 2015-16. Statistics Division, Pakistan Bureau of Statistics, Islamabad.

Government of Pakistan. (1990-2017). Agricultural statistics of Pakistan. Ministry of National Food Security and Research (Economic Wing), Government of Pakistan, Islamabad. view at Google scholar

Government of Pakistan. (2018). Economic survey of Pakistan. Economic Adviser's Wing, Finance Division, Islamabad. view at Google scholar / view at publisher

Goswami, S. N., \& Challa, O. (2006). Socio-economic factors affecting land use in India. Agri. Situ. India, 60(10), 615-623. view at Google scholar / view at publisher 
Govt. Khyber Pakhtunkhwa. (2014). Khyber Pakhtunkhwa development statistics. Planning and Development Department, Bureau of Statistics, Peshawar.

Gujarati, N. D. (2004). Basic econometrics. The McGraw-Hill Companies, United States. view at Google scholar

Hazell, P. B. R. (1989). Changing patterns of variability in world cereal production. In: J.R. Anderson and P.B.R. view at Google scholar

Hong-juan, J., Yan-jie, Y., \& Guo-qiang, Z. (2017). Hydrogen Peroxide Involved in Tip Growth of Wheat (TriticumAestivum) Root Hairs by High Concentration Chlorogenic Acid. Canadian Journal of Agriculture and Crops, 2(1), 22-33.

Jehangir, M. K., Ahmad, S., \& Saddozai, K. N. (2008). Economic analysis of wheat profitability in Peshawar Valley. NWFP. Pak. j. life Soc. Sci., 6(2), 112-117. view at Google scholar

Mehra, S. (1981). Instability in Indian agriculture in the context of the new technology. International Food Policy Research Institute. Research Report. 25. Washington, USA. view at Google scholar

Mitra, A. K. (1990). Agricultural production in Maharashtra: growth and instability in the context of new technology. Economic and Political Weekly, 25(52), 146-164. view at Google scholar

Parthasarathy, G. (1984). Growth rates and fluctuations of agricultural production: a district-wise analysis in Andhra Pradesh. Economic and Political Weekly, 19(26), 74-84. view at Google scholar

Ray, S. K. (1983). An empirical investigation of the nature and causes for growth and instability in Indian agriculture: 1950-80. Indian Journal of Agricultural Economics, 38(4), 459-474. view at Google scholar

Singh, A. K., \& Issac, J. (2018). Impact of climatic and non-climatic factors on sustainable livelihood security in Gujarat state of India: A statistical exploration. Agriculture and Food Sciences Research, 5(1), 30-46.

Wasim, M. P. (2001). Agricultural growth and instability in major crops production: a province wise analysis in Pakistan. The Asian Economic Review, 43(2), 294-314. view at Google scholar

Wasim, M. P. (2011). Trends, growth and variability of major fruit crops in Baluchistan. Journal of Agricultural and Biological Science, 6(12), 27-36. view at Google scholar 